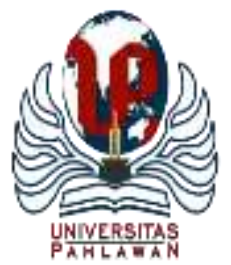

Edukatif : Jurnal Ilmu Pendidikan Volume 4 Nomor 1 Tahun 2022 Halm 1140 - 1149

EDUKATIF: JURNAL ILMU PENDIDIKAN

Research \& Learning in Education

https://edukatif.org/index.php/edukatif/index

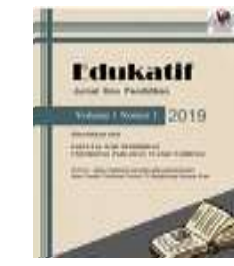

\title{
Studi Kualitatif Pengaruh Faktor Individu terhadap Kelulusan Computer Based Test Uji Kompetensi Mahasiswa Program Profesi Dokter
}

\author{
Huda Marlina Wati ${ }^{1 凶}$, Lasiah Susanti ${ }^{2}$, May Valzon ${ }^{3}$ \\ Universitas Abdurrab, Pekanbaru 1,2,3,

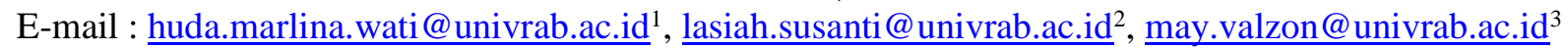

\begin{abstract}
Abstrak
Penyelenggaraan uji kompetensi merupakan salah satu upaya penjaminan mutu lulusan dokter yang dihasilkan institusi pendidikan dokter. Ujian ini dilaksanakan dalam bentuk computer based test (CBT) dan Objective Structured Clinical Examination (OSCE). Kelulusan CBT selalu lebih rendah dibandingkan kelulusan OSCE. Pada periode November 2019 tercatat kelulusan CBT nasional hanya mencapai 59\%, sedangkan OSCE mencapai 93\%. Angka kelulusan CBT firsttaker dari Universitas Abdurrab hanya 54\% pada periode yang sama. Pada penelitian dilakukan eksplorasi pengaruh faktor individu terhadap kelulusan CBT. Data penelitian merupakan data kualitatif yang diperoleh dengan focus group discussion (FGD). Mahasiswa yang dilibatkan antara lain lulusan firsttaker, lulusan retaker dan mahasiswa yang masih belum lulus UKMPPD. Selain itu juga dilakukan wawancara dosen serta studi dokumen terkait riwayat akademik mahasiswa. Hasil yang diperoleh yaitu beberapa faktor individu yang berpengaruh antara lain motivasi, kepercayaan diri, fokus pada tujuan, manajemen waktu, strategi belajar, sikap positif dan penguasaan materi. Dibutuhkan sinergi antar faktor individu untuk hasil maksimal.
\end{abstract}

Kata Kunci: faktor individu, CBT, UKMPPD, studi kualitatif, uji kompetensi.

\begin{abstract}
UKMPPD is a quality assurance effort to ensure medical graduates competence as a medical doctors. This test is carried out in two form, a computer based test (CBT) and Objective Structured Clinical Examination (OSCE). Unfortunately, CBT pass rate is always lower than OSCE. This research aim to explore the influence of individual factors on CBT performance. Researchers collected qualitative data by focus group discussion (FGD) involving Abdurrab University medical students who have been registered as UKMPPD CBT participants. This research also collected data from lecturer interviews and documents related to academic history. As results, there are several individual factors influencing UKMPPD CBT performance: motivation, self-confidence, focus on goals, time management, learning strategies, positive character and medical knowledge proficiency. Positive individual factors indicate a strong individual character. However, these individual factors could synergize each other so it should be noticed to retain each of them in adequate level.
\end{abstract}

Keywords: competency test, CBT, individual factor, UKMPPD

Copyright (c) 2022 Huda Marlina Wati, Lasiah Susanti, May Valzon

$\square$ Corresponding author

Email : huda.marlina.wati@univrab.ac.id

DOI $\quad:$ https://doi.org/10.31004/edukatif.v4i1.2061

ISSN 2656-8063 (Media Cetak)

ISSN 2656-8071 (Media Online) 
1141 Studi Kualitatif Pengaruh Faktor Individu terhadap Kelulusan Computer Based Test Uji Kompetensi Mahasiswa Program Profesi Dokter - Huda Marlina Wati, Lasiah Susanti, May Valzon

DOI: https://doi.org/10.31004/edukatif.v4i1.2061

\section{PENDAHULUAN}

Ujian Kompetensi Mahasiswa Pendidikan Profesi Dokter (UKMPPD) merupakan ujian akhir yang harus ditempuh oleh mahasiswa kedokteran sebagai prasyarat mendapatkan gelar dokter. UKMPPD diikuti oleh mahasiswa pendidikan profesi yang telah menyelesaikan seluruh stase klinisnya. Kelulusan UKMPPD mutlak diperlukan untuk mendapatkan sertifikat tanda registrasi yang berfungsi sebagai lisensi bagi praktisi dokter (Undang-Undang Republik Indonesia Nomor 20 Tahun 2013 tentang Pendidikan Kedokteran ). Dengan demikian, penyelenggaraan UKMPPD merupakan salah satu upaya penjaminan mutu bahwa lulusan dokter yang dihasilkan institusi pendidikan dokter memenuhi kompetensi minimal yang disyaratkan oleh undang-undang (Indonesia, 2013). Berdasarkan data Panitia Nasional Uji Kompetensi Mahasiswa Pendidikan Profesi Dokter (PNUKMPPD) tentang hasil ujian kompetensi Tahun 2019, didapatkan bahwa angka kelulusan CBT hanya 59,81\%, jauh lebih rendah dibandingkan angka kelulusan OSCE yang mencapai 92,91\% pada periode yang sama (Panitia Nasional Ujian Kompetensi Mahasiswa Program Profesi Dokter, 2019). Pada periode yang sama, kelulusan computer based test (CBT) peserta ujian firsttaker Fakultas Kedokteran dan Ilmu Kesehatan Universitas Abdurrab (FKIK Univrab) hanya 54,3\%, sedangkan kelulusan OSCE peserta first taker mencapai 79,1\% (Fakultas Kedokteran dan Ilmu Kesehatan Universitas Abdurrab, 2020).

Mahasiswa yang mengikuti UKMPPD adalah mahasiswa tahap akhir pendidikan profesi yang telah menyelesaikan seluruh stase klinis sehingga seharusnya dapat melewati nilai batas lulus ujian. Rendahnya angka kelulusan pada ujian high stakes seperti UKMPPD merupakan tantangan bagi institusi. Angka kelulusan merupakan monitor dan feedback atas proses pembelajaran yang telah berlangsung (Shumway \& Harden, 2003) (Kickert, Stegers-Jager, Meuwisse, Prinzie, \& Arends, 2018).

Banyak studi meneliti tentang UKMPPD, namun hanya ada beberapa studi yang membahas mengenai faktor yang berkaitan dengan kelulusan UKMPPD, diantaranya mengenai self regulated learning dan kaitannya dengan hasil CBT UKMPPD (Simaremare, 2019). Penelitian lain juga meneliti mengenai self efficacy dan kaitannya dengan kelulusan UKMPPD (Supriyati, Setiawati, \& Sandayanti, 2019). Kedua studi ini menemukan korelasi positif signifikan antara self regulated learning dan self efficacy dengan hasil UKMPPD. Namun, belum melakukan eksplorasi lebih lanjut mengenai persepsi responden penelitian mengenai kedua faktor tersebut. Dengan demikian peneliti merasa perlu menelusuri lebih lanjut dan menganalisis tentang faktor-faktor yang mempengaruhi kelulusan mahasiswa profesi dokter dalam UKMPPD CBT khususnya faktor individu pada lingkungan FKIK Univrab.

\section{METODE PENELITIAN}

Penelitian ini merupakan penelitian kualitatif dengan rancangan fenomenologi. Pengumpulan data dilakukan dengan Focus Group Discussion (FGD) dan atau wawancara semi terstruktur. Partisipan FGD merupakan mahasiswa atau alumni FKIK yang telah mengikuti UKMPPD. Terdapat 4 kelompok FGD dengan total 16 partisipan. FGD 1 merupakan kelompok partisipan yang lulus first taker. FGD 2 merupakan kelompok partisipan yang lulus retaker. FGD 3 merupakan kelompok partisipan yang belum lulus UKMPPD. Terakhir FGD 4 adalah kelompok gabungan mahasiswa yang telah lulus dan belum lulus UKMPPD. Selain itu juga dilakukan wawancara pada 3 orang dosen yang terlibat dalam pembelajaran, penyelenggaraan pendidikan profesi dan atau UKMPPD. Selain itu juga dilakukan studi dokumen mengenai riwayat akademik mahasiswa sebagai bentuk triangulasi. Adapun data mengenai karakteristik responden FGD dapat dilihat pada tabel 1. 
1142 Studi Kualitatif Pengaruh Faktor Individu terhadap Kelulusan Computer Based Test Uji Kompetensi Mahasiswa Program Profesi Dokter - Huda Marlina Wati, Lasiah Susanti, May Valzon

DOI: https://doi.org/10.31004/edukatif.v4i1.2061

Tabel 1. Karakteristik Partisipan FGD

\begin{tabular}{llllll}
\hline Kode & Inisial & Jenis kelamin & IPK sarjana & IPK profesi & $\begin{array}{l}\text { Kelulusan } \\
\text { UKMPPD }\end{array}$ \\
\hline P1, FGD1 & ND & perempuan & 3,47 & 3,72 & lulus first taker \\
\hline P2, FGD1 & WEP & laki-laki & 3,38 & 3,56 & lulus first taker \\
\hline P3, FGD1 & DF & perempuan & 3,46 & 3,8 & lulus first taker \\
\hline P4, FGD1 & SA & laki-laki & 3,12 & 3,59 & lulus first taker \\
\hline P5, FGD1 & IR & laki-laki & 2,75 & 3,46 & lulus first taker \\
\hline P1, FGD2 & CH & laki-laki & 2,6 & 3,39 & lulus retaker \\
\hline P2, FGD2 & WP & laki-laki & 2,6 & 3,32 & lulus retaker \\
\hline P3, FGD2 & MR & perempuan & 2,64 & 3,36 & lulus retaker \\
\hline P1, & MS & laki-laki & 2,5 & 3,16 & belum lulus \\
FGD3 & & laki-laki & 2,82 & 3,4 & belum lulus \\
\hline P2, & PAP & & & \\
FGD3 & & perempuan & 2,76 & 3,42 & belum lulus \\
\hline P3, FGD3 & APS & perempuan & 2,74 & 3,48 & belum lulus \\
\hline P4, & DSA & & & \\
FGD3 & & perempuan & 3,2 & 3,44 & lulus retaker \\
\hline P1, FGD4 & SN & laki-laki & 2,77 & 3,19 & belum lulus \\
\hline P2, FGD4 & TA & perempuan & 2,75 & 3,36 & belum lulus \\
\hline P3, FGD4 & AJ & laki-laki & 2,74 & 3,39 & belum lulus \\
\hline P4, FGD4 & FRR & & &
\end{tabular}

Penelitian ini juga melibatkan 3 orang dosen yang merupakan dosen pengajar yang terlibat dalam pembelajaran baik pada tahap sarjana tahap profesi serta 2 orang diantaranya juga merupakan koordinator pendidikan di dua rumah sakit tempat pelaksanaan pendidikan profesi. Data yang dikumpulkan dianalisis secara tematik. Tiga tahapan analisis data yaitu reduksi data (data reduction), penyajian data (data display) dan penarikan kesimpulan atau verifikasi (conclution drawing/verification). Uji keabsahan data yang dilakukan pada penelitian meliputi uji kredibilitas, uji transferabilitas, uji depandibilitas dan uji konfirmabilitas.

Uji kredibilitas akan dicapai dengan proses triangulasi dan member check. Uji transferabilitas dilakukan dengan menuliskan laporan penelitian berupa uraian yang rinci, jelas, sistematik dan dapat dipercaya. Uji dependabilitas dilakukan dengan melibatkan satu orang peneliti anggota selama pengumpulan dan analisis data.

\section{HASIL DAN PEMBAHASAN PENELITIAN}

Terdapat berbagai faktor individu masing-masing peserta yang dapat mempengaruhi kelulusan uji kompetensi mahasiswa program profesi dokter, khususnya saat ujian CBT. Faktor individu ini antara lain motivasi, kepercayaan diri, fokus pada tujuan, strategi belajar, manajemen waktu, sikap positif dan penguasaan materi. Motivasi berupa keinginan kuat untuk dapat segera lulus menjadi dokter serta keinginan untuk dihargai sebagai lulusan dokter yang setara dengan lulusan negeri menjadikan mahasiswa lebih semangat untuk belajar. Selain itu, mahasiswa yang mengikuti UKMPPD ini adalah mahasiswa yang sudah menyelesaikan pendidikan tahap sarjana dan profesi sehingga seharusnya mampu' untuk menyelesaikan ujian dengan baik. Jadi, perbedaan mendasar antara mahasiswa yang telah lulus UKMPPD dan yang masih belum 


\section{Studi Kualitatif Pengaruh Faktor Individu terhadap Kelulusan Computer Based Test Uji Kompetensi Mahasiswa Program Profesi Dokter - Huda Marlina Wati, Lasiah Susanti, May Valzon DOI: https://doi.org/10.31004/edukatif.v4i1.2061}

adalah pada motivasi dan semangat untuk belajar. Motivasi ini berkaitan erat dengan passion seseorang untuk melakukan sesuatu.

“....Ya guna UKMPPD ini kan supaya penyetaraan ya .Walaupun kita swasta, ya tau sendiri kadang kadang mahasiswa swasta ini suka disepelekan gitu "alah lulusan swasta, beda dengan lulusan negri...”(P1,FGD1).

"UKMPPD itu penting Dok, karena itu untuk uji kompetensi kita sehingga nanti apapun kampus kita dari kampus negri ataupun swasta,baik itu akreditasi A ataupun B ataupun C. Jadi ketika kita lulus dari UKMPPD, kita dianggap layak untuk terjun di dunia yang sebenarnya Dok. Tidak ada diskriminasi lagi di dunia kerja' (P2,FGD3).

"... lebih kepada motivasi mereka ya. Kalau masalah pintar bodoh, karena mereka udah selesai jenjang perkuliahan, ga mungkinlah.. satu lagi apakah mereka itu memang memanfaatkan waktu untuk bisa segera...Toh kalau ilmu yang dikasih (red: dosen), sama kan untuk semuanya.” (W1).

Kepercayaan diri bahwa akan dapat menyelesaikan ujian dengan baik merupakan salah satu faktor yang mempengaruhi kelulusan UKMPPD. Mahasiswa yang percaya diri maka akan lebih tenang ketika ujian, sebaliknya mahasiswa yang kurang percaya diri merasa ragu-ragu dalam menjawab, padahal seperti yang diakui oleh sebagian besar peserta UKMPPD, kasus-kasus yang dihadapi saat ujian sebenarnya familiar dan juga sudah dipelajari, namun bila soalnya dibaca berulang kali, maka jawabannya bisa berubah lagi. Selain itu, kegagalan pada ujian UKMPPD sebagai firsttaker, menyebabkan berkurangnya rasa percaya diri. Krisis percaya diri ini merupakan salah satu hal yang harus ditaklukkan oleh peserta retaker agar dapat menyelesaikan ujian dengan seharusnya pada periode berikutnya.

"Kalau menurut saya pribadi faktor yang mempengaruhi pertama adalah kepercayaan diri. Artinya ketika kita percaya diri, kita akan lebih yakin dalam mengisi dan lebih tenang dalam menjawab dengan dikondisikan dengan waktu yang ada..."(M1, FGD4).

Fokus pada tujuan akan menentukan alokasi waktu menjelang ujian. Mahasiswa yang fokus pada tujuan akan memprioritaskan ujian sehingga akan mengalokasikan waktu untuk persiapan ujian dan menyusun strategi belajar. Bahkan beberapa diantaranya menarik diri dari sosial media untuk sementara karena khawatir akan mengganggu persiapan ujian.

"Memang harus fokus, gak bisa tidak. Saya sendiri belajar itu berhenti itu tidur aja Dok. Kalau seandainya ngantuk, kalau saya dulu itu, mencoba lari-lari di kamar, terus push up, belajar lagi...” (P5, FGD1).

"Manajemen waktu dok, misalnya mungkin boleh dikasi tau main mainnya boleh, tapi cuma weekend aja, terus kalau desty kemaren emang off sosmednya dok, karena sosmed itu wasting time sekali kan, tak sadar tiba tiba buka instagram udah 4 jam, jadi semua aplikasi sosmed dihapus. (P3, FGD1).

"Saya kemarin dok setelah gagal yang CBT itu lebih banyak latihan-latihan soal dok. Soal yang dari kampus windi bahas, atau dari soal yang dari lembaga-lembaga bimbel..” (P2,FGD2).

“...Sebagian teman kan harus 200 soal dalam 1 hari atau 100 soal, kalau saya nggak bisa gitu, jadi memang harus tau kemampuannya sendiri gitu...harus memang pahami dulu kondisi kita itu gimana..." (P1, FGD3). 


\section{Studi Kualitatif Pengaruh Faktor Individu terhadap Kelulusan Computer Based Test Uji Kompetensi Mahasiswa Program Profesi Dokter - Huda Marlina Wati, Lasiah Susanti, May Valzon DOI: https://doi.org/10.31004/edukatif.v4i1.2061}

Cara mahasiswa mengalokasikan waktu selama persiapan ujian berpengaruh pada performa ujian. Mahasiswa mengakui bahwa usaha tidak mengkhianati hasil. Selain itu kelompok mahasiswa firsttaker juga mengurangi penggunaan smartphone untuk hal-hal yang tidak berhubungan dengan persiapan UKMPPD. "Manajemen waktu dok, misalnya mungkin boleh dikasi tau main mainnya boleh, tapi cuma weekend aja, terus kalau desty kemaren emang off sosmednya dok, karena sosmed itu wasting time sekali kan, tak sadar tiba tiba buka instagram udah 4 jam, jadi semua aplikasi sosmed dihapus. Kemaren, terus tidak pacaran.. Karena memang membuang waktu dan tidak sadar gitu, karena kan punya target, kita harus punya , bisa batasi diri lah dok, itu intinya sebenarnya dok. Sosial media lah sekarang ini apalagi kan Dok, main hape ngak sadar, targetnya ngerjain soal 100, baru 10 main hape bentarrr cuman, ternyata empat jam”. (P3, FGD1).

Strategi dan kebiasaan belajar merupakan salah satu faktor mempersiapkan diri dalam menghadapi ujian. Sebagian besar mahasiswa memilih untuk berlatih mengerjakan soal-soal UKMPPD. Menurut mahasiswa dan alumni, kasus yang diujikan sebagian besar familiar, namun karena di pendidikan profesi bentuknya praktek sehingga cara efektif dalam mempersiapkan ujian adalah berlatih mengerjakan soal dan membahas materi yang terdapat dalam soal tersebut hingga tuntas.

"Kalau saya pribadi sih nggak ada lagi belajar teori, ngak ada lagi belajar fisiologi ngak ada lagi belajar patofisiologi ngak ada lagi belajar, ngak ada lagi yang kek gitu tu , langsung belajar soal aja. Jadi selama beberapa bulan terakhir itu bahas soal, setiap hari bahas soal" (P2.FGD1).

Sikap positif dalam menghadapi masalah merupakan salah satu poin penting yang mempengaruhi performa UKMPPD CBT. Hal ini termasuk mencoba untuk tetap tenang dan berpikiran positif ketika menghadapi kendala saat ujian berlangsung. Bahkan bagi peserta retaker, sikap ini sangat berpengaruh dan dapat mengganggu rasa percaya diri saat mengikuti ujian periode berikutnya.

“...Artinya disitu yang dirasakan harus berjuang untuk move on. Artinya kita tetap review lagi, ada yang masih kurang... Mungkin untuk retaker beratnya lagi ke mental tadi dok, karena susahnya luar biasa ngerjakan ujian saat menjadi retaker. Karena kalau udah belakangan, maksudnya menjelang dekat ujian itu retaker merasa, nanti gagal lagi. Nanti udah belajar lagi, salah lagi. Apalagi menjelang ujian kayaknya, wih kok buyar. Hafalan berantakan. Kek gitu kan dok. Jadi kembali lagi kek mana kita yakin, tenang aja didalam, kek gitu dok. Jadi soal pertama aja kita merasa nanti salah lagi ni kek mana, kok gitu ya. Nanti muncul lagi ni, salah lagi, ga lulus lagi. Ha disitu lah retaker di soal pertama udah merasakan yang kayak gitu dok. Jadi tenang, pokoknya janji ama diri kek gitu. Jadi tenang, kerjakan...”(P1, FGD4).

“....Pola pikirnya itu, pola pikir seorang, harusnya sudah masuk kedalam S2.. Kadang-kadang mereka gak-gak sadar gituloh. Disangkanya mereka belajarnya harus sama seperti yang harus di suapin satu-satu, yang harus selalu kita dorong terus, jadi yang saya katakan kalian sudah S2 jadi harus punya pola pikir tentu jauh berbeda dengan sebelumnya yang kalian masih praklinik sebelumnya...”(W2).

Penguasaan materi yaitu teori-teori mengenai ilmu kedokteran dasar, ilmu kedokteran klinis, ilmu pelayanan kesehatan dan keterampilan klinis yang diperoleh mahasiswa selama pendidikan tahap sarjana dan tahap profesi juga berpengaruh terhadap keberhasilan ujian kompetensi. Menurut kelompok mahasiswa yang lulus firsttaker, selama masa jeda persiapan UKMPPD, tidak cukup waktu untuk mengulang teori sehingga ilmu yang telah diperoleh dalam masa pendidikan baik tahap sarjana dan profesi sangat penting.

“ Intinya kalau nggak belajar di kampus ya nggak bakal paham apa yang mau mereka pelajari gitu kan. Intinya ya pelajaran ilmu yang kita dapatkan dikampus sebagai basic, basic supaya kita paham, apa yang kita mau 


\section{Studi Kualitatif Pengaruh Faktor Individu terhadap Kelulusan Computer Based Test Uji Kompetensi Mahasiswa Program Profesi Dokter - Huda Marlina Wati, Lasiah Susanti, May Valzon \\ DOI: https://doi.org/10.31004/edukatif.v4i1.2061}

bahas di soal, kalau kita nggak tau sama sekali ilmu tentang kedokteran, kita mau ngebahas soal ya bingung juga ibaratnya..." (P2,FGD1).

."Kalau dari OSCE nya dok. Itu yang saya alami dan kawan rata-rata yang udah dua kali, tiga kali udah tau clue nya, oh kayak gini rupanya OSCE. Materinya tidak jauh-jauh beda sama di koas.” (P1, FGD3).

"Kebanyakan belajar sendiri dok. Baca-baca teori sendiri dok. Hampir ada sekitar $6070 \%$ ada dapat di koas dok, tapi di stase IGD rata-rata dok. Stase-stase yang tanpa ada IGD nya, sama sekali tidak ada dok. apalagi kita dirumah sakit yang lumayan besar dok, kebetulan saya dapat di Dumai dulu, jadi kasus-kasus kecil agak kurang dok. Kompetensi-kompetensi 4A jarang..” (P2, FGD.

"Kalau dari saya waktu koas itu mungkin ada Sebagian yang dibahas, tapi kebanyakan tidak ada yang dibahas, karena tidak ada jumpa kasusnya, karena kalau kita apain UKMPPD kayak kita belajar sendiri dan juga bimbingan diluar juga, dan kita belajar sendiri aja dok, ga ada dari koas. Jadi intinya untuk UKMPPD itu kita belajar sendiri dan ikut-ikut bimbel. Kalau koasnya ya seperti itulah dok.” (P4, FGD3).

Motivasi merupakan faktor pendorong individu untuk melakukan tindakan agar mencapai tujuan yang diharapkan. Harapan untuk segera menyelesaikan pendidikan profesi dan memperoleh gelar dokter merupakan motivasi yang kuat. Bagi mahasiswa kedokteran dari institusi pendididikan kedokteran swasta, keinginan untuk diakui dan setara dengan lulusan dokter dari institusi negeri juga merupakan motif yang kuat agar bisa lulus UKMPPD first taker (Hayat, Salehi, \& Kojuri, 2018). Motivasi berhubungan positif dengan performa akademik dan ujian. Mahasiswa dengan motivasi yang tinggi cenderung memiliki semangat juang yang lebih baik serta berupaya untuk mengatasi semua masalah yang menghadang agar dapat mewujudkan apa yang diharapkannya (Lertwilaiwittaya, Sitticharoon, Maikaew, \& Keadkraichaiwat, 2019).

Motivasi akan berhubungan erat dengan faktor individu lainnya misalnya fokus pada tujuan (Hidayatullah, 2021). Mahasiswa yang memiliki motivasi kuat akan fokus pada tujuan dan dapat mengendalikan diri serta konsisten pada kegiatan-kegiatan yang mendukung pembelajaran dan persiapan dalam menghadapi ujian (Kusurkar, Cate, Vos, Westers, \& Croiset, 2012; Ahmady, Khajeali, Sharifi, \& Mirmoghtadaei, 2019). Pada FGD dengan kelompok mahasiswa yang lulus firsttaker, didapatkan bahwa kelompok mahasiswa tersebut konsisten menghabiskan sebagian besar waktunya untuk belajar, menghindari teman-teman yang akan membuatnya lalai belajar, menolak ajakan untuk sekedar istirahat minum keluar bila target pembelajarannya belum selesai. Konsistensi ini termasuk dengan mengurangi intensitas penggunaan media sosial, bahkan sampai menghapus sementara aplikasi media sosial dari perangkat smartphone. Menurut mahasiswa yang telah lulus UKMPPD firsttaker aktivitas sosial media merupakan salah satu kegiatan yang tanpa disadari akan menghabiskan waktu (Hayat, Salehi, \& Kojuri, 2018; Lertwilaiwittaya, Sitticharoon, Maikaew, \& Keadkraichaiwat, 2019; Firmansyah, 2021).

Faktor keyakinan diri merupakan faktor positif yang mendukung kelulusan UKMPPD CBT. Mahasiswa yang percaya diri maka akan lebih tenang ketika ujian, sebaliknya mahasiswa yang kurang percaya diri merasa ragu-ragu dalam menjawab, padahal seperti yang diakui oleh sebagian besar peserta UKMPPD, kasus-kasus yang dihadapi saat ujian sebenarnya familiar dan juga sudah dipelajari (Guntern, Korpershoek, \& van der Werf, 2017; Klassen \& Klassen, 2018). Sebuah penelitian menyebutkan bahwa kepercayaan diri menjadi salah satu faktor penting dalam pembentukan kompetensi dan dapat menjadi penanda dalam kemungkinan kelulusan ujian pada mahasiswa kedokteran. Kepercayaan diri ini dapat menghilangkan keraguan dalam pelaksanaan ujian dan menurunkan kecemasan atau stres menghadapi ujian (Egwu, Dimkpa, Orji, Njoku, Eni, \& Besong, 2011). 


\section{Studi Kualitatif Pengaruh Faktor Individu terhadap Kelulusan Computer Based Test Uji Kompetensi Mahasiswa Program Profesi Dokter - Huda Marlina Wati, Lasiah Susanti, May Valzon \\ DOI: https://doi.org/10.31004/edukatif.v4i1.2061}

Rasa percaya diri merupakan salah satu masalah utama yang harus diselesaikan oleh peserta retaker. Pada FGD dengan kelompok mahasiswa yang sudah lulus UKMPPD setelah ujian yang berikutnya diketahui bahwa ketika kegagalan dalam ujian pertama, mahasiswa menjadi kehilangan rasa percaya diri bahkan dapat menjadi trauma emosional (Guntern, Korpershoek, \& van der Werf, 2017). Kurangnya keyakinan diri membuat peserta retaker menjadi ragu dengan jawaban ujiannya. Pentingnya teman-teman dan feedback yang benar akan membantu mahasiswa mendapatkan kepercayaan dirinya. Sebuah penelitian menyebutkan bahwa mahasiswa yang pernah mengalami kegagalan di ujian sebelumnya dan memperoleh nilai kurang memuaskan, maka akan cenderung menurun percaya dirinya (Egwu, Dimkpa, Orji, Njoku, Eni, \& Besong, 2011). Namun demikian, penelitian ini juga menyebutkan bila level persiapan ujian mahasiswa yang pernah gagal ini lebih baik dari sebelumnya, hal ini justru dapat justru berpeluang meningkatkan kepercayaan diri dibandingkan mahasiswa yang baru mengikuti pertama kalinya. Hal ini kemungkinan disebabkan mahasiswa tersebut telah familiar dengan sistem ujian sehingga lebih siap secara mental. Pada dasarnya, sikap atau attitude mahasiswa saat menghadapi masalah merupakan kunci untuk dapat berhasil pada ujian berikutnya. Mahasiswa yang cenderung bersikap negatif seperti yang dikemukakan oleh peserta FGD menyebutkan bahwa terdapat malu, rasa rendah diri ketika gagal pada ujian pertama sehingga sebagian peserta retaker menarik diri dan tidak bersedia belajar dalam kelompok yang sama dengan juniornya. Hal ini tentu tidak menguntungkan karena membatasi mahasiswa saat mempersiapkan diri untuk ujian pada periode berikutnya. Sebaliknya mahasiswa yang bersikap positif akan mengambil pembelajaran dari kegagalan pertamanya dan berusaha mencari lingkungan dan teman-teman yang dapat mendukung tekadnya untuk lulus ujian kompetensi (Guntern, Korpershoek, \& van der Werf, 2017).

Faktor individu ketiga dalam persiapan ujian adalah fokus pada tujuan. Faktor ini dan faktor motivasi akan saling bersinergi dan berhubungan dengan dengan beberapa faktor berikutnya yaitu strategi belajar, manajemen waktu termasuk alokasi waktu untuk belajar (Guntern, Korpershoek, \& van der Werf, 2017). Ketika mahasiswa memiliki motivasi yang tinggi, kemudian fokus pada kelulusan ujian, maka dengan sendirinya mahasiswa akan mengatur waktu untuk fokus belajar. Mahasiswa yang telah lulus baik first taker dan retaker menyebutkan bahwa ketika mereka fokus dan serius pada ujian, maka hampir seluruh waktu digunakan untuk belajar mempersiapkan diri untuk UKMPPD serta diantaranya ada yang sengaja off dari media sosial serta menahan diri untuk kegiatan non akademik selama persiapan UKMPPD (Klassen \& Klassen, 2018).

Mahasiswa yang fokus pada ujian menitikberatkan strategi belajarnya pada pembahasan soal atau contoh soal UKMPPD CBT. Menurut mahasiswa dan alumni, kasus yang diujikan sebagian besar familiar, namun karena saat menjalani pendidikan profesi lebih banyak melakukan performa psikomotor sehingga harus banyak berlatih soal. Sebuah studi menemukan bahwa latihan mengerjakan soal ujian dari bank soal memberikan hasil yang lebih baik daripada mengulang belajar untuk persiapan ujian (Burk-Rafel, Santen, \& Purkiss, 2017).

Pembahasan soal atau contoh soal secara komprehensif berpengaruh terhadap kelulusan UKMPPD CBT. Perbedaan mendasar yang dilakukan kelompok mahasiswa lulusan retaker adalah cara pembahasan soal. Beberapa mahasiswa lulusan retaker menyebutkan bahwa ketika pertama kali mempersiapkan diri untuk UKMPPD CBT, mereka juga mempelajari soal dengan menjawab soal, dengan target jumlah soal yang dijawab sebanyak mungkin. Perbedaannya dengan kelompok lulusan firsttaker yaitu kelompok ini lebih menitikberatkan pada pembahasan soal, bukan sekedar menjawab soal. Membahas soal secara komprehensif berarti menganalisis kasus dalam soal hingga kelima opsi jawaban yang diberikan. Penelitian Lertwilaiwittaya dkk mendapatkan bahwa kelompok dengan skor uji kompetensi sangat baik adalah kelompok dengan total waktu belajar yang paling tinggi dibanding kelompok lainnya, sedangkan total waktu persiapan yang paling sedikit adalah pada kelompok dengan skor uji kompetensi paling rendah (Lertwilaiwittaya, Sitticharoon, Maikaew, \& Keadkraichaiwat, 2019). Pada penelitian ini, kelompok mahasiswa yang lulus firsttaker 


\section{Studi Kualitatif Pengaruh Faktor Individu terhadap Kelulusan Computer Based Test Uji Kompetensi Mahasiswa Program Profesi Dokter - Huda Marlina Wati, Lasiah Susanti, May Valzon \\ DOI: https://doi.org/10.31004/edukatif.v4i1.2061}

menyebutkan bahwa selama masa persiapan ujian, mereka mengurangi penggunaan smartphone dan sosial media. Hasil ini didukung oleh penelitian yang juga menemukan bahwa kelompok dengan skor uji kompetensi sangat tinggi merupakan kelompok yang paling rendah dalam penggunaan internet untuk hal-hal yang tidak berhubungan dengan akademik selama masa persiapan ujian (Lertwilaiwittaya, Sitticharoon, Maikaew, \& Keadkraichaiwat, 2019).

Faktor individu berikutnya adalah penguasaan materi. Penguasaan materi merupakan faktor yang yang menggambarkan kemampuan mahasiswa dalam mengidentifikasi dan menyelesaikan masalah terkait penyakit pasien. Penguasaan materi identik dengan proses pembelajaran yang dijalani oleh mahasiswa baik pada tahap akademik maupun tahap pendidikan profesi. Pada penelitian ini, mahasiswa dengan riwayat akademik yang baik pada tahap sarjana dan profesi memiliki peluang yang tinggi untuk lulus firsttaker. Riwayat akademik yang mendukung antara lain mampu melewati nilai batas lulus tanpa remedial pada modul-modul tahap sarjana dan dapat menyelesaikan masa studi tepat waktu dengan indeks prestasi kumulatif memuaskan.

Beberapa penelitian yang mendukung bahwa terdapat korelasi antara kemampuan mahasiswa selama proses pembelajaran terhadap performa tes kompetensi. Lebih spesifik beberapa penelitian menunjukkan terdapat korelasi antara kemampuan akademik tahap sarjana dan profesi terhadap performa UKMPPD CBT, dimana korelasi antara kemampuan akademik pada tahap sarjana lebih kuat dibandingkan korelasi antara kemampuan akademik tahap profesi terhadap performa UKMPPD CBT. Hal ini disebabkan karena penilaian modul tahap sarjana lebih menyerupai penilaian UKMPPD CBT, sedangkan pada tahap sarjana lebih menitikberatkan pada penilaian performa atau aspek psikomotor (Pitra \& Akbar, 2019; Pusparini M. , Imaningdyah , Andayani, Mahardika, \& Miranti, 2016; Rezeki, Firdaus, \& Asni, 2020). Meskipun demikian, mahasiswa dengan performa akademik yang kurang selama stase klinis juga berisiko gagal melewati UKMPPD. Interview yang dilakukan dengan dosen pendidik klinik dan koordinator pendidikan di rumah sakit yang menyelenggarakan pendidikan profesi menekankan bahwa mahasiswa yang selama stase klinis kurang proaktif selama pembelajaran serta tampak kurang termotivasi untuk belajar mandiri cenderung gagal pada ujian CBT pertama. Hal ini didukung oleh hasil sistematik review yang dilakukan Rosenthal dkk, bahwa mahasiswa dengan skor yang lebih rendah dari rerata pada enam stase klinis selama menjalani klerkship akan beresiko lebih besar untuk gagal pada ujian kompetensi nasional (Rosenthal, et al., 2019). Sikap negatif mahasiswa selama menjalani masa studi seperti sering terlambat absen selama masa pendidikan formal juga berkorelasi negatif dengan performa uji kompetensi (Ahmady, Khajeali, Sharifi, \& Mirmoghtadaei, 2019; Lertwilaiwittaya, Sitticharoon, Maikaew, \& Keadkraichaiwat, 2019).

Setiap faktor individual di atas saling bersinergi dalam menentukan performa UKMPPD CBT. Untuk mendapatkan hasil UKMPPD yang baik, semua faktor individual harus berada dalam level yang baik (Kusurkar, Cate, Vos, Westers, \& Croiset, 2012). Bila salah satu faktor mengalami penurunan atau bermasalah, maka akan menyeret faktor lain turun sehingga beresiko gagal UKMPPD CBT. Hal ini dianalisis dari hasil UKMPPD peserta retaker. Seperti yang dikemukakan oleh peserta kelompok FGD, peserta retaker berisiko kehilangan rasa percaya diri yang menyebabkan keraguan ketika ujian dan akhirnya gagal kembali. Kehilangan rasa percaya diri juga menyebabkan mahasiswa retaker menarik diri dari proses bimbingan terutama bila harus bergabung dengan junior firsttaker. Namun peserta retaker yang menjadikan kegagalan tersebut sebagai pengalaman yang bisa diperbaiki, cenderung bangkit, tetap percaya diri dan memiliki harapan sehingga mampu mempersiapkan diri lebih baik dan lulus pada ujian periode berikutnya. Temuan penelitian ini dapat dijadikan dasar dalam pengembangan program bimbingan ataupun konseling sehubungan dengan peserta UKMPPD. Namun, temuan ini baru hanya mengeksplorasi beberapa faktor individual saja, dan hanya dilakukan di Universitas Abdurrab saja. 
1148 Studi Kualitatif Pengaruh Faktor Individu terhadap Kelulusan Computer Based Test Uji Kompetensi Mahasiswa Program Profesi Dokter - Huda Marlina Wati, Lasiah Susanti, May Valzon

DOI: https://doi.org/10.31004/edukatif.v4i1.2061

\section{KESIMPULAN}

Hasil eksplorasi faktor individu yang berpengaruh pada performa UKMPPD CBT di antara lain motivasi, kepercayaan diri, fokus pada tujuan, strategi belajar, manajemen waktu, sikap positif dan penguasaan materi. Dimana setiap faktor saling berkaitan satu dan yang lainnya dalam mempengaruhi performa akademik.

\section{UCAPAN TERIMA KASIH}

Terimakasih kepada Kementerian Pendidikan dan Kebudayaan Indonesia, Universitas Abdurrab, dan LPPM universitas Abdurrab yang telah mendanai penelitian ini.

\section{DAFTAR PUSTAKA}

Ahmady, S., Khajeali, N., Sharifi, F., \& Mirmoghtadaei, Z. S. (2019). Factors Related To Academic Failure In Preclinical Medical Education: A Systematic Review. Journal Of Advance In Medical Education And Professionalism, 74-85.

Asghar Hayat, A., Salehi, A., Koj U R I, J., \& Kojuri, J. (2018). Hayat AA Et Al. Role Of Academic Emotions And Motivation Medical Student's Academic Performance: The Role Of Academic Emotions And Motivation.

Burk-Rafel, J., Santen, S., \& Purkiss, J. (2017). Study Behaviors And USMLE Step 1 Performance: Implications Of A Student Self-Directed Parallel Curriculum. Academic Medicine, S67-S74.

Egwu, O. A., Dimkpa, U., Orji, J. O., Njoku, C. O., Eni, E. O., \& Besong, E. (2011). Medical Students - SelfAssessed Confidence Level Before A Major Physiology Examination: Affective Factors In A Nigerian Medical School. Acta Informatica Medica, 153-157.

Fakultas Kedokteran Dan Ilmu Kesehatan Universitas Abdurrab. (2020). Laporan Evaluasi Uji Kompetensi Mahasiswa Program Profesi Dokter Periode Tahun 2019. Pekanbaru.

Firmansyah. (2021). Motivasi Belajar Dan Respon Siswa Terhadap Online Learning Sebagai Strategi Pembelajaran Di Masa Pandemi Covid-19. Edukatif : Jurnal Ilmu Pendidikan, 589-597.

Guntern, S., Korpershoek, H., \& Van Der Werf, G. (2017). Benefits Of Personality Characteristics And Self-Efficacy In The Perceived Academic Achievement Of . Educational Psychology, 733-744.

Hayat, A. A., Salehi, A., \& Kojuri, J. (2018). Medical Student's Academic Performance: The Role Of Academic Emotions And Motivation. Journal Of Advances In Medical Education \& Professionalism, 168-175.

Hidayatullah, A. (2021). Pengaruh Motivasi Belajar Dan Manajemen Kelas Terhadap Hasil Belajar Siswa. Edukatif: Jurnal Ilmu Pendidikan, 1451-1459.

Indonesia, K. K. (2013). Standar Pendidikan Profesi Dokter Indonesia. Konsil Kedokteran Indonesia.

Kickert, R., Stegers-Jager, K., Meuwisse, M., Prinzie, P., \& Arends, L. (2018). The Role Of The Assessment Policy In The Relation Between Learning And Performance. Medical Education, 324-335.

Klassen, R., \& Klassen, J. (2018). Self-Efficacy Beliefs Of Medical Students: A Critical Review. Perspective On Medical Education, 76-82.

Kusurkar, R. A., Cate, O. T., Vos, C. M., Westers, P., \& Croiset, G. (2012). How Motivation Affects Academic Performance: A Structural Equation Modelling Analysis. Advances In Health Sciences Education, 57-69. 
1149 Studi Kualitatif Pengaruh Faktor Individu terhadap Kelulusan Computer Based Test Uji Kompetensi Mahasiswa Program Profesi Dokter - Huda Marlina Wati, Lasiah Susanti, May Valzon DOI: https://doi.org/10.31004/edukatif.v4i1.2061

Lertwilaiwittaya, P., Sitticharoon, C., Maikaew, P., \& Keadkraichaiwat, I. (2019). Factors Influencing The National License Examination Step 1 Score In Preclinical Medical Students. Advan Physiology Education, 306-316.

Panitia Nasional Ujian Kompetensi Mahasiswa Program Profesi Dokter. (2019). Daftar Nilai Hasil Ujian Periode November 2019.

Pitra, D. H., \& Akbar, R. R. (2019). The Correlation Of Preclinical GPA Score In Faculty Of Medicine Of University Of Baiturrahmah With National Board Examination Result. International Journal Of Medical Science And Clinical Invention, 4403-4406.

Pryta, A., \& Simaremare, R. (2019). Ade Pryta R Simaremare. Self-Regulated Learning In Correlation To Learning Outcome Of Computer-Based Test Preparation Of Medical Students SELF-REGULATED LEARNING IN CORRELATION TO LEARNING OUTCOME OF COMPUTER-BASED TEST PREPARATION OF MEDICAL STUDENTS.

Pusparini, M., Imaningdyah , A., Andayani, S. H., Mahardika, Z. P., \& Miranti, D. D. (2016). Hubungan Antara IPK Program Sarjana Kedokteran Dengan Nilai UKMPPD Mahasiswa FKUY. Jurnal Kedokteran Unila, 235-242.

Rezeki, R., Firdaus, \& Asni, E. (2020). Korelasi Indeks Prestasi Kumulatif Dengan Nilai UKMPPD CBT Periode November 2018 - Agustus 2019 Fakultas Kedokteran Universitas Riau. Jurnal Ilmu Kedokteran, 36-41.

Rosenthal, S., Russo, S., Berg, K., Majdan, J., Wilson, J., Grinberg, C., Et Al. (2019). Identifying Students At Risk Of Failing The USMLE Step 2 Clinical Skills Examination. Family Medicine, 483-499.

Shumway, J., \& Harden, R. (2003). AMEE Guide No. 25: The Assessment Of Learning Outcomes For Competenet And Reflective Physician. Medical Teacher.

Simaremare, A. P. (2019). Self Regulated Learning In Correlation To Learning Outcome Of Computer Based Preparation Of Medical Student. Jurnal Pendidikan Kedokteran Indonesia, 136-143.

Supriyati, Setiawati, O. R., \& Sandayanti, V. (2019). Hubungan Antara Self Efficacy (Keyakinankemampuan Diri) Dengan Kelulusan Retaker UKMPPD Di Universitas Malahayati. Holistik Jurnal Kesehatan, 2936.

Undang-Undang Republik Indonesia No. 20 Tahun 2003 Tentang Sistem Pendidikan Nasional. (N.D.). Jakarta: Departemen Pendidikan Nasional Republik Indonesia. 